\title{
Mental disorders and quality of life in pediatric patients with chronic kidney disease
}

\begin{abstract}
Authors
Renata Cristiane Marciano'

Cristina Maria Bouissou Soares $^{2}$

José Silvério Santos

Diniz $^{2}$

Eleonora Moreira Lima ${ }^{2}$

José Maria Penido Silva²

Monica Ribeiro

Canhestro ${ }^{3}$

Andrea Gazzinelli

Oliveira $^{3}$

Carla Duarte $\mathrm{Melo}^{4}$

Cristiane Santos Dias ${ }^{2}$

Humberto Correa ${ }^{5}$

Eduardo Araujo de

Oliveira $^{6}$

${ }^{1}$ Hospital das Clínicas da Universidade Federal de Minas Gerais - HCUFMG,

Department of Mental

Health, Faculdade de

Medicina, UFMG

2Pediatric Nephrology Unit, HCUFMG

${ }^{3}$ Escola de Enfermagem, UFMG

\section{Abstract}

In the last decades there was a striking improvement in survival of children with chronic kidney disease. As life expectancy has increased in children with CKD, concern has risen about its physical, psychological, and social consequences. The aim of this study was to perform a review of the psychological consequences of CKD in the pediatric population, with the focus on mental disorders and on quality of life. We also reviewed studies regarding emotional and social effects and their possible influences on treatment adhesion. Several studies have shown impairment on quality of life and on mental health of these patients. A better understanding of emotional consequences of CKD in pediatric population possibly can reduce the impact of the renal disease on children. Moreover, a comprehensive approach of children and adolescents with CKD might result in a better clinical control and improve treatment adhesion.
\end{abstract}

${ }^{4}$ Fellow at the Scientific Initiation Program, UFMG

${ }^{5}$ Department of Mental Health, Faculdade de

Medicina, UFMG

${ }^{6}$ UFMG

Submitted on: 06/05/2010

Approved on: 07/08/2010

Correspondence to:

Eduardo Araújo de Oliveira.

Hospital das Clínicas - UFMG

Rua Engenheiro Amaro Lanari 389/501

Belo Horizonte - Minas Gerais CEP: $30310-580$

E-mail: eduolive812@gmail. com

The authors received financial support from FAPEMIG, CNPq and CAPES.

We declare no conflict of interest.
Keywords: chronic kidney failure, pediatrics, qualityoflife,kidneytransplantation, dialysis. [J Bras Nefrol 2010;32(3): 309-315 ] CElsevier Editora Ltda.

\section{InTRODUCTION}

In recent years, medical care and the management of children and adolescents with chronic kidney disease (CKD) have significantly developed. As a consequence, there have been considerable changes in the prognosis of these patients and survival.has extended. However, there is still great difficulty in the management of stress and the responsibilities that accompany CKD, as these patients deal with a life of limitations. Additionally, their quality of life (QoL) is significantly impaired due to the demands and restrictions brought on by the clinical condition and treatment. ${ }^{2,3}$ CKD affects many life aspects of these children. On a daily basis, they are submitted to dietetic and hydric restrictions, difficult and invasive treatments, with complex drug treatments and even hospitalizations. It has been observed that they present a higher risk of worse psychosocial performance than their healthy peers. ${ }^{4,5}$ Literature data have shown that these emotional alterations in patients with CKD and their caregivers can also persist in the adult phase. ${ }^{6,7}$ Thus, it can be perceived that the management of these patients represents a challenge for the healthcare team, for the patients and their caregivers. In this context, we have tried to understand the patients' adaptive mechanisms to this new reality. ${ }^{8}$ This review aims at clarifying the main psychosocial effects of CKD in these children and adolescents. The better understanding of these associations constitute an important step in the construction of a more humanized and effective healthcare assistance.

\section{Objective}

To evaluate the emotional effects and the QoL impairment in children and adolescents with CKD that might influence prognosis and clinical control of these patients.

\section{Method}

A literature review was carried out at the Regional Library of Medicine (Biblioteca Regional de Medicina - BIREME) and at PUBMED, using the following key words: 
"Chronic Disease", "Renal Insufficiency, Chronic", "Depressive Disorder", "Depressive Disorder, Major", "Dysthymic Disorders", "Mental Disorders Diagnosed in Childhood", "Quality of Life", "Adolescent", "Child". Articles published from 1980 on were selected. We also selected studies that were reported as being related to those identified at the aforementioned search. All 27 articles published in indexed journals that evaluated the QoL and mental health of children and adolescents with CKD and used valid assessment tools were included.

In the included studies, the main assessment tools used to evaluate the QoL have a validated Portuguese version, are self-applicable and include the pediatric inventory of QoL - PedsQL in their general and specific versions for CKD patient; the childhood QoL questionnaire - AUQUEI - and the SF-36. To evaluate mental health, the Kiddie- SADS, considered the gold-standard for this purpose, was employed, as well as the Strengths \& Difficulties Questionnaire (SDQ), which is self-applicable and works as a screening of the main psychiatric disorders and evaluates the children's skills, mainly from the point of view of sociability; the Child Behavior Checklist (CBCL), which is an inventory of behaviors for children and adolescents; the Trace State Anxiety Inventory (IDATE) for children, among others, such as SCICA and the Rutter scale.

\section{Results and Discussion}

The presence of chronic diseases (CD) during childhood and adolescence significantly increases the risk of emotional and behavioral disorders. ${ }^{9}{ }^{910}$ Although many $\mathrm{CD}$ are considered rare in childhood, it has been estimated that they affect approximately $15 \%$ of the pediatric population. Of this total, approximately $5 \%$ are persistent or recurrent organic CD. ${ }^{11}$ Children with CD can present psychological disorders caused not only by the disease itself, but also by the treatment. These children can also have their daily life modified by several limitations, mainly physical ones, due to the characteristics of the disease that require continuous re-adaptations in the presence of new situations, in addition to the development of strategies for coping with the disease. ${ }^{12,13}$ These children suffer due to the fact that the disease affects not only their lives, but also their families'. ${ }^{14}$ These emotional alterations can be associated with the neurological alterations inherent to the diagnosis itself. However, it can be observed that the emotional disorders presented by the patients are essentially associated with the innate difficulties of living with a CD. ${ }^{15}$ Some studies that used simple interventions showed that stimulating these children to perform activities that are normal for their peers might be beneficial. For instance, in the study by Balen et al., ${ }^{16}$ the children with cancer who spent one week in a summer camp reported improvement in their levels of anxiety and self-esteem.

CKD constitutes an important cause of pediatric morbidity and is associated with significant mortality. In parallel, it causes severe psychosocial damage, which is even more severe in those with congenital disease that need renal replacement therapy (RRT). CKD is invariably quite stressful and has a high impact on the lives of patients and their families. Therefore, it constitutes a predisposing factor for the development of psychiatric pathologies in these patients and their family members, notably in their main caregivers. ${ }^{10}$ On the other hand, the presence of psychiatric comorbidities worsens the prognosis of patients with CKD. Burton et al. found an association between major depression and premature death in CKD patients. ${ }^{17}$ The medical care given to CKD patients have advanced substantially in the last decades. However, the treatment remains quite invasive, requiring profound behavior, cultural and life style changes. The clinical condition of these patients brings on several daily difficulties and limitations. Thus, their increased survival is many times accompanied by the presence of psychiatric comorbidities. ${ }^{18,19}$ Normally, these children present anemia, hyporexia and a tendency toward decreasing their activities, with a worsening in school performance. ${ }^{3}$ Bakr et al. demonstrated that these emotional consequences are not explained by socioeconomic or clinical factors. In this study, the emotional involvement was associated with the difficulty to live with the disease and with altered renal function. ${ }^{20}$

The patients with CKD reported high levels of stress, depression and feelings of hopelessness related to worries concerning their own health and the perception of their limitations. ${ }^{1}$ Brownbridge et al. demonstrated that high levels of depression and anxiety and altered results in personality tests in these patients were associated with a worse therapeutic adherence. ${ }^{21}$ Thus, an important point to be discussed is that the understanding and re-channeling of stress in children with CKD constitute an effective form of relief of their emotional suffering and improvement in their treatment adherence. ${ }^{22}$

According to the literature data, the prevalence of psychiatric alterations among children and adolescents with CKD is quite variable. However, it was 
higher than that observed in the healthy population in most studies. Table 1 summarizes some of the main studies on the psychosocial and QoL impairment in pediatric patients with CKD.

Children with CKD normally present a negative self-image and a feeling of inferiority in relation to their peers. The study by Bakr et al. ${ }^{20}$ used the SCICA, a semi-structured questionnaire that globally evaluates the patient's functionality in nine areas, such as school, friends and family relations in 38 pediatric patients with CKD undergoing conservative treatment and hemodialysis (HD). The prevalence of mental disorders was $52.6 \%$, divided as follows: behavior $18.4 \%$; depression $22.4 \%$; neurocognition disorders $7.7 \%$; anxiety $5.1 \%$, and elimination disorders, $2.6 \%$. When comparing the incidence of psychiatric disorders in patients undergoing dialysis and conservative treatment, the prevalence was $68.4 \%$ and $36.8 \%$, respectively. ${ }^{20}$

Several hypotheses have been suggested to explain this increase in the prevalence of mental disorders. In addition to the stress inherent to CKD and its treatment, studies have pointed out to other factors that contribute to the predisposition to psychiatric disorders in this group. Among them, we can mention the decrease in the levels of the brain-derived neurotrophic factor (BDNF) and the low serum levels of serotonin in CKD patients. They also present uremia, which can be associated with irritability, restlessness, insomnia and delayed development of secondary sexual features..$^{20,23}$ The cognitive function of patients with CKD seems to be worse than that of their healthy peers. This impairment seems to be related to the time of exposition to the disease. The cognitive alterations are mainly related to learning and intelligence. ${ }^{24}$ The young adults with CKD since childhood, particularly those that have undergone dialysis for longer periods, present impaired cognition and reading skills, when compared to their peers. ${ }^{25}$ In the study by Bawden et al., patients with CKD showed mild deficit at tests of intelligence and fine motor skills, when compared to siblings. However, surprisingly, no differences were observed regarding the academic results, memory, behavior and self-esteem. ${ }^{26}$ It constitutes noteworthy information the fact that the consequences of $\mathrm{CKD}$, its treatment and the psychiatric and clinical comorbidities persist after childhood. Patients with CKD in childhood present an increased risk of social and psychiatric comorbidities at the adult age. When comparing healthy adults with those individuals with CKD in childhood, it was observed that a significant number of the latter did not work, had not married and lived longer at their parents' houses. These patients presented a delayed social, psychological and sexual development, in addition to decreased autonomy when adults..$^{27,28}$

In the study of Rosenkranz et al., ${ }^{1} 50 \%$ of the participants informed that the CKD negatively affected their social life. Among these, approximately one-third had sought medical help in the previous five years due to psychiatric and emotional disorders. Few patients reported a stable relationship with the opposite sex. ${ }^{2}$ In this other study, the level of dependence found in patients with CKD was high. Growth and sexual development delay was also observed, as well as a much lower fertility rate, when compared to that of the general population.

Therapy adherence constitutes another challenge for these pediatric patients. To follow the proposed treatment means to be submitted to hydric and dietetic restrictions, complex posologic regimens and invasive therapies. The study by Wolff et al. emphasized psychosocial factors related to adherence. It was observed that the patients with worse emotional and social performance usually demonstrated a tendency to not follow medical recommendations. ${ }^{29}$ In this same study of transplanted kidney patients that declared they did not follow the medical recommendations, $31 \%$ informed that they did not tolerate the family's interference in their lives and $19 \%$ reported previous attempts at self-extermination and/or serious suicidal thoughts. This author explains that the adolescent with CKD many times does not adhere to the treatment in an attempt to demonstrate autonomy and treatment adherence very often worsens when there is a family crisis. These transplanted patients complained that they felt dependent, disbelieved and that their efforts to adhere to the treatment had been disregarded. ${ }^{29}$ Transplanted children need to deal with the necessity to continuously use immunosuppressive drugs and deal with their side effects. These patients fear the loss of the functioning graft. ${ }^{30}$ It is important to work with the families on the actual expectations of the caregivers and transplanted patients. Although it represents a huge evolution in terms of QoL, the transplant can become a frustrating experience, as the patients and their family members often expect a totally healthy and autonomous life after the procedure. ${ }^{29,31}$

The phase immediately after the transplant is a delicate one, marked by the presence of depression symptoms, low self-esteem and difficulty to understand and deal with the treatment. ${ }^{32}$

Among the social effects of CKD is the significant schooling impairment. Usually, the degree of 


\begin{tabular}{|c|c|c|c|c|}
\hline Table 1 & \multicolumn{4}{|c|}{$\begin{array}{l}\text { COMPILATION OF QUANTITATIVE STUDIES ON THE PSYCHOSOCIAL IMPAIRMENT IN PEDIATRIC PATIENTS WITH CHRONIC KIDNEY } \\
\text { DISEASE (CKD) }\end{array}$} \\
\hline Study & Design & Sample & Place & Results \\
\hline $\begin{array}{l}\text { Reynolds, } \\
1988\end{array}$ & Case-control & $\begin{array}{l}22 \text { families with children } \\
\text { undergoing HD, } 22 \text { families with } \\
\text { children with CKD undergoing } \\
\text { conservative treatment } \\
\text { compared to } 31 \text { controls }\end{array}$ & $\begin{array}{l}\text { United } \\
\text { Kingdom }\end{array}$ & $\begin{array}{l}\text {-- In the HD group: larger number of family } \\
\text { conflicts }\end{array}$ \\
\hline $\begin{array}{l}\text { Reynolds, } \\
1991\end{array}$ & Cross-sectional & $\begin{array}{l}29 \text { transplanted children, } \\
22 \text { undergoing } \mathrm{HD} \text { and } 22 \\
\text { undergoing conservative } \\
\text { treatment }\end{array}$ & $\begin{array}{l}\text { United } \\
\text { Kingdom }\end{array}$ & $\begin{array}{l}\text { After TX: } \\
\text { - Improvement in children's physical health } \\
\text { and behavior } \\
\text { - Improvement in the family's QoL } \\
\text { - Psychological follow-up: better psychosocial } \\
\text { adjustment } \\
\text { TX versus HD: } \\
\text { - Improvement in adjustment, behavior, } \\
\text { mood and social adjustment in the first } \\
\text { group. }\end{array}$ \\
\hline $\begin{array}{l}\text { Rosekranz, } \\
1992\end{array}$ & Cross-sectional & $\begin{array}{l}479 \text { children and adolescents } \\
(31 \% \text { undergoing conservative } \\
\text { treatment, } 14 \% \text { undergoing HD, } \\
9 \% \text { undergoing CAPD and } \\
46 \% \text { TX) }\end{array}$ & Germany & $\begin{array}{l}\text { - } 29 \% \text { of the patients presented some type } \\
\text { of motor or cognitive disability } \\
-26 \% \text { of those older }>16 \text { years had } \\
\text { completed High School } \\
-43 \% \text { of those }>21 \text { years were employed } \\
\text { - } 86 \% \text { of those }>16 \text { years still lived with } \\
\text { caregivers }\end{array}$ \\
\hline $\begin{array}{l}\text { Reynolds, } \\
1993\end{array}$ & Cross-sectional & $\begin{array}{l}45 \text { adults that had been children } \\
\text { with CKD: } 36 \text { transplanted, } \\
2 \text { undergoing CAPD and } 7 \mathrm{HD} \text {, } \\
\text { and } 48 \text { controls }\end{array}$ & $\begin{array}{l}\text { United } \\
\text { Kingdom }\end{array}$ & $\begin{array}{l}\text { Case Group: } \\
\text { - Lower social skills } \\
\text { - Most lived with parents } \\
\text {-Fewer extra-family intimate relationships } \\
\text { - Worse professional skills } \\
\text { - Higher rates of unemployment } \\
\text { - Early onset of the disease associated to a } \\
\text { worse social performance } \\
\text { - QoL equivalent to that of the control group }\end{array}$ \\
\hline $\begin{array}{l}\text { Brownbridge, } \\
1994\end{array}$ & Cross-sectional & $\begin{array}{l}60 \text { children and adolescents } \\
\text { undergoing HD and CAPD and } \\
\text { their parents }\end{array}$ & $\begin{array}{l}\text { United } \\
\text { Kingdom }\end{array}$ & $\begin{array}{l}\text { Low adherence to treatment associated with: } \\
\text { - Anxiety and depression } \\
\text { - Adolescence } \\
\text { - Increased dialysis duration } \\
\text { - Low socioeconomic level } \\
\text { - Family structure consisting of single } \\
\text { parents }\end{array}$ \\
\hline Fielding, 1999 & Cross-sectional & $\begin{array}{l}60 \text { children and adolescents } \\
\text { undergoing HD and CAPD and } \\
\text { their parents }\end{array}$ & $\begin{array}{l}\text { United } \\
\text { Kingdom }\end{array}$ & $\begin{array}{l}\text { - Higher rates of anxiety were observed in } \\
\text { larger families }\end{array}$ \\
\hline $\begin{array}{l}\text { Goldstein, } \\
2006\end{array}$ & Cross-sectional & $\begin{array}{l}85 \text { children with CKD and } 95 \\
\text { parents, compared to healthy } \\
\text { children from the PedsQL } \\
\text { validation study }\end{array}$ & United States & $\begin{array}{l}\text { - Lower QoL scores of patients with CKD in } \\
\text { all domains } \\
\text { - Transplanted patients presented better } \\
\text { scores in the physical and psychosocial } \\
\text { domains }\end{array}$ \\
\hline $\begin{array}{l}\text { Fadrowski, } \\
2006\end{array}$ & Cohort & 78 adolescents with CKD & United States & $\begin{array}{l}\text { QoL improvement was associated with } \\
\text { growth } \\
\text { - Worsening in the QoL was directly } \\
\text { associated with worsening in renal function }\end{array}$ \\
\hline $\begin{array}{l}\text { Bakr, } \\
2007\end{array}$ & Cross-sectional & $\begin{array}{l}19 \text { children undergoing } \\
\text { conservative treatment and } 19 \\
\text { undergoing HD }\end{array}$ & Egypt & $\begin{array}{l}\text { Prevalence of: } \\
\text { - Psychiatric disorders: } 52.6 \% \text { (more } \\
\text { frequent in patients undergoing HD) } \\
\text { - Adjustment disorders: } 18.4 \% \\
\text { - Depression: } 10.3 \%\end{array}$ \\
\hline $\begin{array}{c}\text { Buyan, } \\
2010\end{array}$ & Case-control & $\begin{array}{l}211 \text { children and adolescents } \\
\text { with CKD and } 129 \text { parents, } \\
\text { compared to } 232 \text { healthy controls } \\
\text { and } 156 \text { parents }\end{array}$ & Turkey & $\begin{array}{l}\text { Case Group: } \\
\text { - Lower QoL scores in all domains, except } \\
\text { the physical one TX versus HD: } \\
\text { - Better self-image and social relations in the } \\
\text { first group }\end{array}$ \\
\hline
\end{tabular}

$\mathrm{HD}=$ hemodialysis $; \mathrm{CKD}=$ chronic kidney disease; $\mathrm{TX}=$ kidney transplant; $\mathrm{QoL}=$ quality of life; $\mathrm{CAPD}=$ continuous ambulatory peritoneal dialysis. 
schooling in these patients is lower than that of their healthy peers. It has been demonstrated that children and adolescents with CKD present a higher degree of school absenteeism. ${ }^{33}$ The parents of children with CKD undergoing hemodialysis (HD) report a worse academic performance of their children in comparison to those undergoing conservative treatment and in the control group. It is also noteworthy the low school performance of siblings of children and adolescents with CKD. ${ }^{9}$ Another point to be considered is the association between the worsening in the QoL and the morbimortality of CKD patients. ${ }^{34,35}$ QoL is a multidisciplinary concept that consists in the perception of the individual of his/her position in life, in the context of the culture and system of values in which he/she lives and in relation to his/her objectives, expectations, standards and concerns. QoL worsening interferes with the prognosis of these patients. In relation to the type of treatment used, the worse scores of QoL were observed in patients undergoing dialysis, in most studies. In the study by Gerson et al., adolescents undergoing dialysis with end-stage CKD reported a worse QoL, with worse impairment of the physical domain in relation to transplanted patients with functioning graft. ${ }^{36,37}$ In a recent study by Buyan et al., ${ }^{38}$ in which 211 children with CKD were compared to healthy controls, the first presented significant impairment of the QoL in relation to the latter. Regarding the type of treatment, the transplanted patients presented a higher degree of self-esteem and preserved social skills in comparison to those undergoing dialysis. In the study by Mckenna et al. ${ }^{39}$ the PedsQL was used to measure the QoL of 64 children with CKD, of which results were statistically lower in all domains in comparison to healthy controls. Similar results were obtained at the study by Goldstein et al. ${ }^{40}$ which used the same tool. The patients' perception of their clinical condition and alterations regarding the general population was also a determinant factor for the QoL impairment.

The study by Fadrowski et al..$^{23}$ showed a probable association between an increase in height and QoL improvement in relation to the physical domain. In this study, adequate levels of hematocrit and albumin were associated with a better QoL. On the other hand, a decrease in the glomerular filtration rate (GFR) was associated with a significant impairment of the QoL in adolescents with CKD. This author associated a worse performance in the psychosocial domain of the QoL to the dialysis treatment and older age.

Adolescence is considered a difficult period, marked by conflicts in search of one's autonomy, which culminates with the redefinition of the individual towards adult life introduction. These conflicts are considered inherent to the normal adolescence syndrome. In patients with CKD, these conflicts are aggravated by the difficulty in managing the disease and the feelings of rebellion and denial of one's physical condition and its treatment. In the case of CKD, considering its multiple physical and psychosocial effects, this phenomenon is usually observed at higher intensity. In patients with CKD, adolescence usually brings about a worsening in clinical control and therapeutic adherence. Moreover, there is an additional stressor, which is the change in the healthcare team that cares for the patient. A worsening in the clinical control has been demonstrated when these patients were referred to healthcare teams that treated adult patients. ${ }^{2}$ In the study by McDonagh, the CKD itself, plus the side effects of the medications, the school absenteeism and the psychosocial alterations, notably the low self-esteem observed in these patients, resulted in growth and development retardation, pubertal delay and worse cognitive performance.

In this study, the adolescents with CKD presented worse social and sexual performance than the control group. ${ }^{41}$ These pubertal patients showed more concern regarding the normal adolescence questions, such as alcoholism, illicit-drug use, sex, weight, contraception and wanted these subjects to be debated during the treatment. ${ }^{2,42}$

It was observed that the adolescents with CKD presented a high level of dependence, associated to the overprotection by family members and teachers. When these patients became adults, they reported that their inclusion in the treatment and clinical decisions and adequate explanations were considered very important contributions in their own management of the disease. ${ }^{2}$

\section{Conclusion}

Pediatric patients with CKD are frequently affected by mental disorders at higher frequency when compared to the general population. This fact is due to the disruptions in the family dynamics, the troublesome treatment and the chronic disease itself. These patients also demonstrated a worse school performance, low self-esteem and difficulty to establish relationships with their peers. The reviewed studies showed that the children undergoing dialysis treatment had a worse emotional performance in comparison to those undergoing the conservative treatment and transplanted patients. The mental and emotional 
health of the pediatric patients with CKD is a determinant factor on the disease course, prognosis and therapeutic success.

In this context, aiming at improving healthcare assistance, it is mandatory to perform further studies to identify new risk factors that can impair the QoL and mental health of these patients.

\section{Acknowledgements}

The present study was supported by Pro-Reitoria de Pos-Graduaçao of UFMG through CAPES/PRPQ/ UFMG. The authors would like to thank FAPEMIG and $\mathrm{CNPq}$ for the financial support given to the study participants. The authors also would like to thank the interdisciplinary team for their dedication to the children and adolescents participating in the Interdisciplinary Program of Chronic Kidney Failure (CKF) Prevention and Assistance of the Pediatric Nephrology Unit of HCUFMG.

\section{References}

1. Rosenkranz J, Bonzel KE, Bulla M et al. Psychosocial adaptation of children and adolescents with chronic renal failure. Pediatr Nephrol 1992; 6:459-63.

2. Reynolds JM, Morton MJ, Garralda ME, Postlethwaite RJ, Goh D. Psychosocial adjustment of adult survivors of a pediatric dialysis and transplant programme. Arch Dis Child 1993; 68:104-10.

3. Soliday E, Kool E, Lande MB. Family environment, child behavior, and medical indicators in children with kidney disease. Child Psychiatry Hum Dev 2001; 31:279-95.

4. Lavigne JV, Faier-Routman J. Psychological adjustment to pediatric physical disorders: a meta-analytic review. J Pediatr Psychol 1992; 17:133-57.

5. Holden EW, Chmielewski D, Nelson CC, Kager VA, Foltz L. Controlling for general and disease-specific effects in child and family adjustment to chronic childhood illness. J Pediatr Psychol 1997; 22:15-27.

6. Fielding D, Brownbridge G. Factors related to psychosocial adjustment in children with end-stage renal failure. Pediatr Nephrol 1999; 13:766-70.

7. Aldridge MD. How do families adjust to having a child with chronic kidney failure? A systematic review. Nephrol Nurs J 2008; 35:157-62.

8. Darbyshire P, Oster C, Henning P. Children and young people experiences of chronic renal disease: a review of the literature, methodological commentary and an alternative proposal. J Clin Nurs 2006; 15:751-60.

9. Reynolds JM, Garralda ME, Jameson RA, Postlethwaite RJ. How parents and families cope with chronic renal failure. Arch Dis Child 1988; 63:821-6.

10. Eiser C. Psychological effects of chronic disease. J Child Psychol Psychiatry 1990; 31:85-98.

11. Mendonça MB, Ferreira EAP. Adesão ao tratamento da asma na infância: dificuldades enfrentadas por cuidadoras. Rev Bras Crescimento Desenvolv Hum 2005; 15:56-68.
12. Jones JG. Compliance with pediatric therapy. A selective review and recommendations. Clin Pediatr (Phila) $1983 ; 22: 262-5$.

13. La Greca AM. Issues in adherence with pediatric regimens. J Pediatr Psychol 1990; 15:423-36. 14. Eiser C, Berrenberg JL. Assessing the impact of chronic disease on the relationship between parents and their adolescents. J Psychosom Res 1995; 39:109-14.

15. Breslau N. Depressive symptoms, major depression, and generalized anxiety: a comparison of self-reports on CES-D and results from diagnostic interviews. Psychiatry Res 1985; 15:219-29.

16. Balen R, Fielding D, Lewis I. Activity Camps for Children with Cancer. Children and Society 1996; 10:317-23.

17. Burton HJ, Kline SA, Lindsay RM, Heidenheim AP. The relationship of depression to survival in chronic renal failure. Psychosom Med 1986; 48:261-9.

18. Fukunishi I, Kudo H. Psychiatric problems of pediatric end-stage renal failure. Gen Hosp Psychiatry 1995; 17:32-6.

19. Fukunishi I, Honda M. School adjustment of children with end-stage renal disease. Pediatr Nephrol 1995; 9:553-7.

20. Bakr A, Amr M, Sarhan A et al. Psychiatric disorders in children with chronic renal failure. Pediatr Nephrol 2007; 22:128-31.

21. Brownbridge G, Fielding D. An investigation of psychological factors influencing adherence to medical regime in children and adolescents undergoing hemodialysis and CAPD. Int J Adolesc Med Health 1989; 4:7-18.

22. Wolcott DL. Organ transplant psychiatry: psychiatry's role in the second gift of life. Psychosomatics 1990; 31:91-7.

23. Fadrowski J, Cole SR, Hwang W et al. Changes in physical and psychosocial functioning among adolescents with chronic kidney disease. Pediatr Nephrol 2006; 21:394-9.

24. Bale JF, Jr., Siegler RL, Bray PF. Encephalopathy in young children with moderate chronic renal failure. Am J Dis Child 1980; 134:581-3.

25. Groothoff JW, Grootenhuis M, Dommerholt A, Gruppen MP, Offringa M, Heymans HS. Impaired cognition and schooling in adults with end stage renal disease since childhood. Arch Dis Child 2002; 87:380-5.

26. Bawden HN, Acott P, Carter J et al. Neuropsychological functioning in end-stage renal disease. Arch Dis Child 2004; 89:644-7.

27. Henning P, Tomlinson L, Rigden SP, Haycock GB, Chantler C. Long term outcome of treatment of end stage renal failure. Arch Dis Child 1988; 63:35-40.

28. Grootenhuis MA, Stam H, Last BF, Groothoff JW. The impact of delayed development on the quality of life of adults with end-stage renal disease since childhood. Pediatr Nephrol 2006; 21:538-44.

29. Wolff G, Strecker K, Vester U, Latta K, Ehrich JH. Noncompliance following renal transplantation in children and adolescents. Pediatr Nephrol 1998; 12:703-8.

30. Grimm PC, Ettenger R. Pediatric renal transplantation. Adv Pediatr 1992; 39:441-93.

31. Griffin KJ, Elkin TD. Non-adherence in pediatric transplantation: a review of the existing literature. Pediatr Transplant 2001; 5:246-9. 
32. Reynolds JM, Garralda ME, Postlethwaite RJ, Goh D. Changes in psychosocial adjustment after renal transplantation. Arch Dis Child 1991 ;66:508-13.

33. Eiser C, Eiser JR, Town C, Tripp JH. Discipline strategies and parental perceptions of preschool children with asthma. Br J Med Psychol 1991; 64:45-53.

34. Cagney KA, Wu AW, Fink NE et al. Formal literature review of quality of life instruments used in end-stage renal disease. Am J Kidney Dis 2000; 36:327-36.

35. Gerson AC, Furth SL, Neu AM, Fivush BA. Assessing associations between medication adherence and potentially modifiable psychosocial variables in pediatric kidney transplant recipients and their families. Pediatr Transplant 2004; 8:543-50.

36. Gerson AC, Riley A, Fivush BA et al. Assessing health status and health care utilization in adolescents with chronic kidney disease. J Am Soc Nephrol 2005; 16:1427-32.

37. Gerson A, Hwang W, Fiorenza J et al. Anemia and health-related quality of life in adolescents with chronic kidney disease. Am J Kidney Dis 2004; 44:1017-23.
38. Buyan N, Turkmen MA, Bilge I et al. Quality of life in children with chronic kidney disease (with child and parent assessments). Pediatr Nephrol 2010; 25:1487-96.

39. McKenna AM, Keating LE, Vigneux A, Stevens S, Williams A, Geary DF. Quality of life in children with chronic kidney disease-patient and caregiver assessments. Nephrol Dial Transplant 2006; 21:1899-905.

40. Goldstein SL, Graham N, Burwinkle T, Warady B, Farrah R, Varni JW. Health-related quality of life in pediatric patients with ESRD. Pediatr Nephrol 2006; 21:846-50

41. McDonagh JE. Child-adult interface. The adolescent challenge. Nephrol Dial Transplant 2000; 15:1761-5.

42. Choquet M, Du Pasquier Fediaevsky L, Manfredi R. Sexual behavior among adolescents reporting chronic conditions: a French national survey. J Adolesc Health $1997 ; 20: 62-7$. 